\title{
Disciplina e controle dos alunos como bases necessárias para o êxito da experimentação pedagógica nas classes-piloto de matemática do Colégio Estadual da Bahia (1966-1969)
}

\author{
Discipline and control of students as necessary bases for the success of \\ pedagogical experimentation in mathematics laboratory classes at the \\ Bahia State High School (1966-1969)
}

\author{
MARIANA MORAES LOBO PINHEIRO \\ Universidade Federal da Bahia | UFBA \\ JANICE CÁSSIA LANDO \\ Universidade Estadual do Sudoeste da Bahia | UESB \\ ANDRÉ LUIS MATTEDI DIAS \\ Universidade Federal da Bahia | UFBA
}

\begin{abstract}
Resumo Neste artigo, abordaremos alguns aspectos da experimentação pedagógica realizada nas classes piloto do Colégio Estadual da Bahia entre 1966 e 1969. Destacaremos certos "princípios"e certa"filosofia da educação" que fundamentaram este projeto a partir da análise das declarações feitas pela sua coordenadora, professora Lêda Jesuíno dos Santos, e pelas professoras Jolândia Serra Vila e Vera Lúcia da Conceição Baqueiro Wasconcellos, que lecionaram matemática nestas classes piloto. Argumentaremos que estes "princípios" " "filosofia da educação" caracterizaram-se pela afirmação da disciplina e do controle dos alunos como bases necessárias para o êxito da experimentação pedagógica, que se concretizaram de modo específico nas técnicas psicopedagógicas de acompanhamento utilizadas fora das salas de aula e nas metodologias e didática utilizadas nas salas de aula. Compararemos esta afirmação com a disciplina e o controle análogos que as autoridades do governo ditatorial do período impuseram sobre estudantes, professores e autoridades educacionais locais, bem como com os as reconhecidas bases liberais e democráticas da concepção original de John Dewey, que foi trazida para o Brasil por Anísio Teixeira e Isaías Alves, este último, fundador, diretor e professor da Faculdade de Filosofia da Bahia, onde se formaram e atuaram as referidas professoras.
\end{abstract}

Palavras-chave experimentação pedagógica - classes piloto - Colégio da Bahia - ensino de matemática - história do ensino.

\begin{abstract}
In this paper, we discuss some aspects of pedagogical experimentation in mathematics laboratory classes at the State High School of Bahia between 1966 and 1969. We highlight "principles" and certain "philosophy of education" that were the bases of the project, analyzing interviews with its coordinator, professor Lêda Jesuino dos Santos, and its mathematics teachers, Jolândia Serra Vila and Vera Lúcia da Conceição Baqueiro Wasconcellos. We argue that student discipline and control were necessary bases for the success of pedagogical experimentation, as reflected in the psycho-
\end{abstract}


pedagogical techniques adopted to monitor the students out of classrooms, as well as in the methodologies and didactics adopted in the classrooms. We compare such tactics with analogous ones violently leveled against students, teachers, professors and local educational authorities by the dictatorial Brazilian government authorities of the period. We also compare such discipline and control with recognized liberal and democratic principles of the original conceptions of John Dewey, brought to Brazil by Anísio Teixeira and Isaías Alves, this last the first director and professor of the Faculty of Philosophy of Bahia, where Lêda Jesuino, Jolândia Vila and Vera Wasconcellos graduated and worked.

Keywords pedagogical experimentation - laboratory classes - mathematics teaching - State High School of Bahia - history of teaching.

\title{
Um trajeto da experimentação pedagógica até o Brasil
}

Um trajeto da experimentação pedagógica teve início no Teacher's College da Universidade de Colúmbia, nos Estados Unidos, devido a John Dewey, e foi continuado no Brasil por educadores que lá estiveram entre o final da década de 1920 e o início dos anos 1930. Este início deve-se à noção de experimentação pedagógica concebida por John Dewey (1859-1952) no final do século XIX:

\begin{abstract}
Nevertheless a school conducted by a department of a university must have another aspect. From the university standpoint, the most important part of its work is the scientific - the contribution it makes to the progress of educational thinking. The aim of educating a certain number of children would hardly justify a university in departing from the tradition which limits it to those who have completed their secondary instruction. Only the scientific aim, the conduct of a laboratory, comparable to other scientific laboratories, can furnish a reason for the maintenance by a university of an elementary school. Such a school is a laboratory of applied psychology. That is, it has a place for the study of mind as manifested and developed in the child, and for the search after materials and agencies that seem most likely to fulfill and further the conditions of normal growth. ${ }^{1}$
\end{abstract}

Para John Dewey, as escolas laboratório teriam no trabalho científico de experimentação pedagógica sua mais importante contribuição para o progresso do pensamento educacional e somente isso justificaria que fossem mantidas por universidades. Entre 1896 e 1904, John Dewey implantou e dirigiu uma escola laboratório na Universidade de Chicago ${ }^{2}$, onde realizou experiências pedagógicas que serviram de fundamento para seus escritos posteriores ${ }^{3}$. Em 1904, Dewey deixou Chicago e foi para a Universidade de Colúmbia, onde foi implantada a escola laboratório Lincoln School em 19174:

In the 1920s and 1930s the Lincoln School was the most closely watched experimental school in the educational world, making solid contributions in the work of laboratory schools. It provided a select number of Teachers College students with clinical teaching experience, engaged in curriculum design and development, and provided an observation and demonstration site for teachers from around the United States and abroad. Its own experimental research institute promoted staff development and student teaching, and it distributed its printed materials in national journals and in mass mailings to schools throughout the United States. ${ }^{5}$

Realizando pesquisa experimental, design e desenvolvimento curricular, observações e demonstrações para professores, esta escola laboratório permaneceu ativa nas décadas de 1920 e 1930, quando educadores brasileiros estagiaram no Teacher's College da Universidade de Colúmbia, dentre os quais os baianos Anísio Spínola Teixeira (19001971), entre 1927 e 1928, e Isaías Alves de Almeida (1888-1968), entre 1930 e $1931 .{ }^{6}$

Quando foi Diretor Geral de Instrução Pública do Distrito Federal (1931-1935), já manifestando a forte influência que John Dewey exerceria nas suas ideias e ações educacionais ${ }^{7}$, Anísio Teixeira adotou a noção de experimentação 
pedagógica ao fundar o Instituto de Educação do Rio de Janeiro em 1932, que contava com Jardim de Infância, Escola Primária, Escola Secundária e Escola de Professores. ${ }^{8}$

De modo diferente, da sua passagem pela Universidade de Colúmbia, Isaías Alves trouxe para as suas ideias e ações educacionais a influencia de Edward Lee Thorndike, outro expoente do Teacher's College, autoridade em testes de inteligência, tema ao qual ele já se dedicara mesmo antes da viagem aos Estados Unidos e que continuaria a se dedicar no decorrer da sua carreira. Todavia, isto não impediu que tivesse contato com as ideias e experiências de John Dewey sobre experimentação pedagógica e que as adotasse quando concebeu a Escola de Aplicação da Faculdade de Filosofia da Bahia em $1944^{9}$

Anísio Teixeira e Isaías Alves atuaram colaborativamente, pelo menos, em dois momentos importantes de suas carreiras. Em 1928, Isaías Alves fez palestras para professores sobre "Medidas da inteligência e dos resultados escolares" em eventos promovidos por Anísio Teixeira, Diretor da Instrução Pública do Estado da Bahia. Posteriormente, em 1931, logo depois que Anísio Teixeira assumiu a Diretoria Geral de Instrução Pública do Distrito Federal, Isaías Alves tornou-se chefe da Seção de Testes e Medidas, responsável pela elaboração, padronização e aplicação experimental de testes em crianças das escolas cariocas até 1934, quando desentendeu-se com Anísio Teixeira em decorrência dos resultados dos testes, das suas interpretações e implicações educacionais, e deixou 0 cargo. ${ }^{10}$

Portanto, a expertise que Isaías Alves desenvolvera sobre os testes de inteligência e as medidas escolares, ampliada e aprofundada pela influência de Edward L. Thorndike durante sua passagem pelo Teacher's College, que fora inicialmente motivo para a sua aproximação com Anísio Teixeira, tornou-se posteriormente um dos motivos para 0 afastamento entre ambos. Por outro lado, a concepção de experimentação pedagógica de John Dewey permaneceu como herança compartilhada das passagens de Anísio Teixeira e Isaías Alves pelo Teacher's College. No primeiro caso, na concepção do Instituto de Educação do Distrito Federal em 1932, no segundo caso, na concepção da Escola de Aplicação da Faculdade de Filosofia da Bahia em 1944. Em ambos os casos, a experimentação pedagógica aparece, por um lado, como fundamento empírico para os desenvolvimentos teóricos das ciências da educação, por outro, como fundamento prático para a formação dos professores. Isto está explícito no Decreto n. 3.810, de 19 de março de 1932, que criou o Instituto de Educação do Distrito Federal e no Regimento do Ginásio Anexo da Faculdade de Filosofia da Bahia, aprovado em 31 de julho de 1944."1

Entretanto, somente após o Decreto 9.053 de 1946 que as faculdades de filosofia brasileiras ficaram obrigadas a manter um ginásio de aplicação destinado à prática docente dos alunos matriculados no curso de didática. Mesmo assim, este decreto não fazia qualquer referência à experimentação pedagógica. Além disso, durante muito tempo, somente a Faculdade Nacional de Filosofia, no Rio de Janeiro, desde 1948, e a Faculdade de Filosofia da Bahia, desde 1949, mantiveram funcionando efetivamente escolas de aplicação. Após duas décadas de existência da lei, existiam apenas oito colégios de aplicação vinculados às faculdades de filosofia. ${ }^{12}$

Luiz Narciso Alves de Mattos, catedrático de didática geral e especial, foi diretor do Colégio de Aplicação da Faculdade Nacional de Filosofia de 1948 a 1965. Assim como Anísio Teixeira e Isaías Alves, estudou educação nos Estados Unidos entre 1926 e 1931, trazendo de volta para o Brasil a influência de John Dewey e o apreço pela sua noção de experimentação pedagógica. Luiz de Mattos e Isaias Alves eram próximos pela formação, fé e atuação católica, assim como pelas ideias modernizadoras que tinham acerca do papel da didática na formação dos professores e da importância da experimentação pedagógica para a constituição das ciências da educação. Para Luiz de Mattos, assim como para Isaías Alves, a didática desempenharia importância primordial na formação docente na medida em que estabeleceria as orientações fundamentais para a racionalização do trabalho docente, possibilitando que o ensino se distanciasse da tradição, da rotina e do empirismo. Ambos defendiam também uma pedagogia experimental como bases para as ciências da educação. Efetivamente, Luiz de Mattos desenvolveu um projeto de didática experimental ao longo de sua carreira, envolvendo a formação de professores na cadeira de didática geral e especial e no ensino secundário no Colégio de Aplicação. ${ }^{13}$

Em 1949, Luiz de Mattos visitou a Faculdade de Filosofia da Bahia e testemunhou as dificuldades que Isaías 
Alves enfrentou na tentativa de implementar as suas ideias sobre didática e experimentação pedagógica na formação de professores e no Ginásio de Aplicação. Os professores mais experimentados da Faculdade estavam ocupados com outras cadeiras e a catedrática de didática geral, Edith Mendes da Gama e Abreu, desenvolvia uma atividade política intensa que limitava sua dedicação ao trabalho docente e científico. Por outro lado, a assistente de didática especial da matemática, Martha Maria de Sousa Dantas, que assumira a subdiretoria do Ginásio de Aplicação junto com ele, ainda era muito jovem e não possuía a experiência necessária. Isaías Alves solicitou a Luiz de Mattos que indicasse um professor do Rio de Janeiro para permanecer por um ano na Bahia, mas isto não foi possível, porque também no Rio de Janeiro não havia professores disponíveis. ${ }^{14}$

Portanto, a dificuldade com o corpo docente da Faculdade foi uma das razões pelas quais a experimentação pedagógica não foi efetivamente realizada antes da década de 1960, mesmo prevista no regimento do Ginásio de Aplicação. A outra razão, talvez a mais importante, está diretamente relacionada com a legislação educacional brasileira vigente no período, muito rígida e restritiva, que dificultava ou impedia a experimentação pedagógica.

Somente em 1958, que houve um impulso para implantação de classes experimentais, quando o MEC baixou instruções que regulamentavam a sua natureza e organização ${ }^{15}$. De um modo geral, foram realizadas experiências que pretendiam desenvolver alternativas pedagógicas para as dificuldades decorrentes da expansão quantitativa do ensino secundário. Contudo, estas experiências mostraram-se conservadoras, na medida em que focaram na complexidade e excepcionalidade técnico-pedagógica de reduzido alcance quantitativo, porque a legislação limitou as experiências ao Colégio Pedro II e às escolas de aplicação das faculdades de filosofia, em salas de aula com até 30 alunos, ao mesmo tempo que alegações orçamentárias impediram a generalização dos resultados para a rede escolar. ${ }^{16}$

Na Bahia, mais precisamente, em Salvador, a implantação de classes experimentais para o desenvolvimento de inovações pedagógicas entre 1947 e 1974 foi tema de um evento específico de caráter histórico em 1982, durante 0 qual foram relatadas sete experiências:

Tabela 1 Experiências educacionais baianas na década de $1960^{17}$

\begin{tabular}{ll} 
Instituição & Período \\
\hline Escola Parque & 1947 a 1964 \\
\hline Colégio Santa Bernadete & 1960 a 1967 \\
\hline Colégio de Aplicação (UFBA) & 1964 a 1967 \\
\hline Classes Pilotos CECIBA & 1966 a 1969 \\
\hline CIAT & 1968 a 1970 \\
\hline GEMPA & 1968 a 1971 \\
\hline Escola Polivalente & 1972 a 1974 \\
\hline
\end{tabular}

Neste trabalho, daremos atenção especial às classes piloto de matemática implantadas pelo Centro de Ensino de Ciências da Bahia (CECIBA) no Colégio Estadual da Bahia entre 1966 e 1969. Contudo, antes que ocorressem estas classes piloto, um projeto de experimentação pedagógica já tivera início em uma classe de matemática no Colégio de Aplicação da Faculdade de Filosofia da UFBA no ano letivo de 1965. Este projeto foi concebido e desenvolvido por Martha Dantas, professora de didática especial da matemática, que liderou uma equipe de professoras do Colégio de Aplicação, que passaram a integrar a Seção Científica de Matemática do CECIBA depois da sua fundação em novembro de 1965. Por isso, antes de examinarmos as experimentações realizadas no Colégio da Bahia, acompanharemos rapidamente como Martha Dantas travou seu primeiro contato com a experimentação pedagógica e com as classes piloto no Centro Internacional de Estudos Pedagógicos de Sèvres, na França, em 1953. 


\section{Um trajeto das classes piloto até a Bahia}

Martha Maria de Sousa Dantas (1925-2011) formou-se em matemática na Faculdade de Filosofia da Bahia, obtendo o bacharelado em 1947 e a licenciatura em 1948. Em 1949, foi nomeada pelo diretor Isaías Alves subdiretora do Ginásio de Aplicação, quando este começou a funcionar efetivamente. Obviamente, como Isaías Alves possuía muitas atribuições como diretor e professor da Faculdade de Filosofia, além de membro do Conselho Federal de Educação, Martha Dantas tornou-se diretora efetiva do Ginásio, sob a supervisão do seu mentor.

Para entendermos porque Isaías Alves confiou missão tão importante para Martha Dantas, uma jovem e recémformada professora de matemática, é necessário compreender as relações entre a tradição e a modernização vigentes na Bahia naquele momento histórico. Assim como Isaías Alves e Anísio Teixeira, Martha Dantas era filha de aristocrática família de proprietários de terras e políticos, católica por formaç̧ão, fé e atuação. Portanto, possuía os predicados sociais e culturais exigidos pelo ponto de vista tradicional de Isaías Alves para conduzir, junto com ele, a modernização profissional e científica que pretendia para a formação de professores na Faculdade de Filosofia e no Ginásio de Aplicação. Ao contrário de Ramakrishna Bagavan dos Santos, formado em matemática na primeira turma em 1945, também professor assistente na Faculdade de Filosofia, que não era baiano, não era filho de uma família aristocrática, não era católico e era socialista, tendo sido por estas razões preterido por Martha Dantas. ${ }^{18}$

Em 1953, um ano após ser nomeada assistente de didática especial da matemática por Isaías Alves, Martha Dantas empreendeu longa viagem com intuito de tomar conhecimento in loco do que vinha acontecendo na Europa no âmbito educacional, particularmente, em relação ao ensino da matemática, alguns anos depois do término da ll Guerra. Visitou a Inglaterra, a Bélgica e a França. ${ }^{19}$

Na França, Martha Dantas realizou um estágio no Centro Internacional de Estudos Pedagógicos de Sèvres ${ }^{20}$, onde ficou impressionada com as atividades promovidas pela Associação de Professores de Matemática do Ensino Público (APMEP). Na França, aquele foi um período marcado por sucessivos e acalorados debates, inicialmente, em torno das propostas de reforma educacional oriundas da comissão ministerial Langevin-Wallon (1944-1947), posteriormente, pelos sucessivos e sucedâneos projetos de reforma educacional. ${ }^{21}$ Martha Dantas teve intenso contato com Edmée Hatinguais, diretora do Centro de Sèvres, que depois visitou a Faculdade de Filosofia da Bahia. Também interagiu intensamente com Lucienne Felix e Marceline Dionot, professoras de matemática e líderes da APMEP, que era porta-voz do desenvolvimento do ensino científico, em geral, e do ensino das matemáticas, em particular. A APMEP organizou enquetes, encontros, reflexões que reforçavam o discurso geral predominante ao longo dos anos 1950, sobre a necessidade de cientistas e técnicos para assegurar o desenvolvimento econômico e a modernização da França.

Estas ações da APMEP também estavam de acordo com o movimento internacional de reforma do ensino da matemática promovido pela Organização Europeia de Cooperação Econômica (OECE) e pela UNESCO. No boletim da APMEP, foram divulgados os eventos da Comissão Internacional para o Estudo e Melhoramento do Ensino da Matemática (CIEAEM), criada em 1952, e da Comissão Internacional para a Instrução Matemática (ICMI), das quais Lucienne Felix e Marceline Dionot faziam parte. Finalmente, a APMEP engajou-se também nas Jornadas Internacionais de Formação sobre o Ensino da Matemática, organizadas em 1955 no Centre International d'Etudes Pédagogiques de Sèvres (CIEP) $)^{22}$.

As ações da APMEP não se restringiram ao âmbito institucional, à divulgação de eventos, mas visaram também promover a renovação dos conteúdos e dos métodos do ensino da matemática. Para introduzir a matemática moderna no ensino secundário, em colaboração com a Sociedade Matemática da França, a APMEP promoveu jornadas de estudos, estágios de formação, ciclos de conferências de professores de faculdades ou de classes preparatórias, cujas apresentações foram publicadas no seu boletim²3.

0 movimento em favor das matemáticas modernas, desenvolvido na APMEP, tinha fortes laços com aquele pela adoção da pedagogia ativa, dos métodos ativos no segundo grau, cujo foco irradiador principal era o CIEP de Sèvres e os seus Cahiers pédagogiques. Alguns dos responsáveis, militantes ou simpatizantes da APMEP eram também professores das classes-nouvelles implantadas em 1945 pelo diretor de ensino do segundo grau, Gustave Monod, que depois, em 1951, passaram a ser chamadas classes piloto: 
Instrument de la réforme : les «lycées-pilotes»

Gustave Monod souhaite aussi créer un nouveau type d'établissement : le «lycée- pilote» (...) Plusieurs de ces lycées-pilotes accueillent les «classes nouvelles » puis les « classes pilotes » mises en place par Charles Brunold, directeur de l'enseignement secondaire à partir de 1951. L'expérience des «classes nouvelles» est, en effet, élargie à l'enseignement du second degré par la circulaire du 30 mai 1952. "Un lycée-pilote est un établissement qui, grâce à l'adhésion de tout le personnel formant une équipe, fonctionne comme un laboratoire permanent d'expérience où s'éprouvent des méthodes plus actives au service de la formation pédagogique des maîtres du second degré 12. » Le lycée de Sèvres devient le modèle de référence des lycées-pilotes ; il est le confluent des recherches des autres établissements ${ }^{24}$.

Portanto, Martha Dantas teve contato e interagiu intensamente com lideranças profissionais e intelectuais dos professores de matemática da França, assim como presenciou in loco uma série de atividades promovidas pela APMEP, particularmente, no Centro de Sèvres. Tanto aquelas professoras francesas, quanto as instituições que tomavam parte, eram porta-vozes do movimento de renovação do ensino da matemática e de reforma da educação secundária francesa em geral. Por um lado, a renovação dos conteúdos e métodos de ensino da matemática, por outro, a pedagogia ativa, os métodos de ensino centrados na atividade e na aprendizagem do estudante, os lycées-pilotes, as classes-nouvelles, as classes-pilotes. Em suma, estabelecimentos que funcionariam como laboratórios permanentes de experimentação, onde seriam testados os métodos ativos a serviço da formação pedagógica dos professores para as escolas secundárias.

Eis, portanto, outro caminho percorrido pela experimentação pedagógica e pelas classes piloto, aquele que teve origem na França, concebido e desenvolvido no Centro Internacional de Sèvres, e que foi trazido por Martha Dantas para a Bahia.

\section{O CECIBA, a experimentação pedagógica e as classes piloto}

As disputas expansionistas de caráter político, econômico e militar, que envolveram países e blocos de alianças entre países, ainda em decorrência dos desdobramentos das guerras mundiais ocorridas na primeira metade do século XX, resultaram na sobrevalorização do domínio e da propriedade do conhecimento científico e tecnológico como estratégicos para o desenvolvimento econômico. Esta valorização foi o elemento comum compartilhado por políticos, cientistas e educadores nas discussões que antecederam a adoção de reformas educacionais em âmbito mundial.

Também no Brasil, o desenvolvimento das ciências e da educação científica tornou-se uma questão estratégica, assumida desta forma pelos diversos governos, desde a retomada democrática em 1946 e mesmo durante a ditadura iniciada em 1964. As políticas educacionais estiveram voltadas para o desenvolvimento econômico, para a industrialização e urbanização que vinham ocorrendo àquela época. Por outro lado, para a população que ainda carregava consigo as discrepâncias sociais e culturais historicamente constituídas, significava a possibilidade de ascensão social.

Na reformulação do ensino secundário, o ensino de ciências e de matemática foi colocado em primeiro plano. É importante destacar aqui a atuação do Instituto Brasileiro de Educação, Ciência e Cultura (IBECC), órgão vinculado ao Ministério das Relações Exteriores, criado em 1946, cujo objetivo principal era executar o programa da UNESCO no Brasil. Nas décadas de 1950 e 1960, associou-se em parceria com a CAPES e as universidades para desenvolver um amplo programa de divulgação de novos métodos de ensino para as disciplinas científicas, que incluía a produção e a tradução de materiais e livros didáticos, a realização de cursos para professores secundários, a produção e venda de equipamentos de laboratórios para as escolas secundárias, dentre outros. ${ }^{25}$

As ações associadas do IBECC e da CAPES ganharam uma nova dimensão em 1965, quando foram criados no Brasil seis Centros de Ensino de Ciências (CECIS) em grandes centros metropolitanos, a saber, Centro de Treinamento para Professores de Ciências de São Paulo (CECISP), Centro de Ciências do Estado da Guanabara (CECIGUA), Centro 
de Treinamento para Professores de Ciências do Rio Grande do Sul (CECIRS), Centro de Treinamento para Professores de Ciências de Minas Gerais (CECIMIG), Centro de Ensino de Ciências do Nordeste (CECINE) e o Centro de Ensino de Ciências da Bahia (CECIBA) ${ }^{26}$

Os referidos centros desempenharam ações que, de um modo geral, pretendiam melhorar o ensino de ciências e matemática em várias regiões do país, numa proposta de renovação ampla do ensino secundário, independente da localidade brasileira, mobilizando, formando, treinando e credenciando professores.

Os centros de ensino de ciências no Brasil, apesar de autônomos, aproximavam-se devido a objetivos em comum, que não se limitavam ao treinamento de professores, mas havia ainda elaboração de projetos, produção de materiais didáticos que foram testados, revisados e, posteriormente, publicados. Por outro lado, a atuação dos centros combinava-se com a realidade da região a qual se dedicavam, o que pode ser encontrado nas fontes orais e escritas que foram localizadas, respeitando as particularidades de cada área de abrangência e caracterizando um processo simultâneo de regionalização.

Na Bahia, o CECIBA desempenhou papel importante em prol da melhoria do ensino secundário baiano, desenvolvendo projetos e materiais didáticos com professores ainda em formação ou já atuantes, que eram capacitados através de cursos oferecidos em parceria com o Ministério de Educação e Cultura (MEC), Secretária de Educação da Bahia (SEC-BA) e com o apoio da Universidade Federal da Bahia (UFBA). Também atuou em escolas em Salvador, desenvolvendo experiências isoladas de implantação de novos métodos para o ensino de matemática em vários colégios: Severino Vieira, Pinto de Carvalho, Antônio Vieira e Nossa Senhora do Carmo. Contudo, enquanto projeto de integração total das disciplinas curriculares do ensino colegial, que recebia assistência pedagógica, destacaramse os trabalhos realizados no Colégio de Aplicação da UFBA e no Colégio Estadual da Bahia, entre os anos de 1966 e $1969 .{ }^{27}$

Antes mesmo de conduzir classes de experimentação pedagógica no Colégio da Bahia, o CECIBA já realizara experimentação pedagógica nas classes do Colégio de Aplicação. Mais do que isto, a experimentação pedagógica começara no Colégio de Aplicação antes mesmo da criação do CECIBA em novembro de 1965. De fato, ao longo do ano letivo de 1965, já fora iniciada uma experiência sistematizada envolvendo conceitos de matemática moderna na $5^{\mathrm{a}}$ série ginasial do Colégio de Aplicação, na classe regida pela professora Maria Augusta Araújo Moreno. ${ }^{28}$

Desde o início, o procedimento adotado foi sempre o mesmo. Uma apostila fora elaborada previamente e depois aplicada em sala de aula pela primeira vez na referida sala de aula no ano letivo de 1965. Os resultados obtidos desta aplicação foram objeto de discussões e avaliações ao longo do ano de 1965. Depois de revisada, em função destas avaliações, a apostila foi publicada em fevereiro de 1966 e novamente aplicada em sala de aula, seguindo-se nova avaliação e revisão ao longo de 1966. Finalmente, a apostila foi publicada sob forma de livro em 1967, com o título Matemática Moderna I. Na introdução, as autoras declararam: "Este livro já foi experimentado dois anos e os resultados que apresentaremos, em breve, aos professores, são bastante animadores". ${ }^{29}$

Portanto, ao contrário do que está bem cristalizado na memória pessoal e coletiva, ao contrário das declarações posteriores da própria Martha Dantas, as experiências no Colégio de Aplicação não foram iniciadas em 1966, mas em 1965, como provam evidências encontradas nos registros dos diários de classe da época, cruzadas com outras evidências encontradas na apostila publicada em 1966 e no livro Matemática Moderna / publicado em 1967.

Em novembro de 1965, foi fundado o CECIBA, cuja Seção Científica de Matemática era coordenada por Martha Dantas e composta pelas mesmas professoras que trabalharam com ela realizando experimentações pedagógicas no Colégio de Aplicação e em outras escolas, de 1966 até 1969, quando o CECIBA teve suas atividades encerradas. ${ }^{30}$

Como o objetivo deste trabalho não é focar nas experimentações pedagógicas conduzidas pelo CECIBA no Colégio de Aplicação, passaremos então a tratar das experimentações pedagógicas nas classes piloto de matemática do Colégio da Bahia, que é verdadeiramente o foco deste trabalho. 


\section{As classes piloto de matemática no Colégio Estadual da Bahia}

A experimentação pedagógica em classes piloto foi desenvolvida no Colégio Estadual da Bahia - também conhecido como Colégio Central - entre 1966 e 1969, fundada por um convênio tríplice entre o MEC, representado por Gildásio Amado, Diretor Geral do Ensino Secundário, a Secretaria de Educação do Estado, representada por Ramakrishna Bagavan dos Santos, assessor da Superintendência do Ensino Médio e a Universidade Federal da Bahia, representada pelo Diretor do CECIBA, professor Antônio Celso Spínola, e pelo professor Pedro Sarno, Coordenador da Seção Científica de Química do CECIBA, ambos do Instituto de Química da UFBA. ${ }^{31}$

Em 1966, houve apenas uma classe piloto, a turma H, que enfrentou uma série de contratempos para o seu funcionamento, dentre as quais, principalmente, uma greve estudantil, que desencadeou uma série de manifestações e protestos naquele ano. É importante destacar que aquele foi um período de grande movimentação e tensão política em decorrência do golpe de estado de 1964 e da implantação da ditadura que governaria o Brasil ainda por vários anos ${ }^{32}$, cuja ação repressiva foi direcionada contra estudantes secundaristas e universitários desde os primeiros momentos. ${ }^{33}$

A greve estudantil de 1966 foi provocada pela proibição da exibição da peça Aventuras e desventuras de um estudante, de autoria do estudante Carlos Sarno e pela suspensão imposta pela diretoria do Central aos integrantes do Grupo Amador de Teatro Estudantil da Bahia, do qual Sarno fazia parte e que encenaria a peça, que abordava problemas da educação brasileira tomando como exemplo a trajetória de um estudante interiorano que enfrentou dificuldades quando chegou para estudar na capital: a matrícula complicada por causa da falta de vagas, a militância que o conclamava à participação política para garantir seus próprios direitos de cidadão e a defesa do regime democrático, mas despertava a repressão do governo ditatorial. Esta foi a primeira grande manifestação estudantil contra a ditadura na Bahia, foi sucedida por uma série de outras, que mobilizaram também intelectuais e a imprensa, que divulgou amplamente os acontecimentos, condenando a violência da repressão. ${ }^{34}$

Em 1967, ocorreu a troca da coordenação geral do projeto - o professor Pedro Sarno foi substituído pela professora Lêda Jesuíno dos Santos ${ }^{35}$, que permaneceu até o final - e novas professoras assumiram as classes piloto de matemática - a professora Lycia da Silva Guimarães lecionou para a turma H, as professoras Jolândia Serra Vila e Vera Lúcia da Conceição Baqueiro Wasconcellos lecionaram para os grupos A e B, a primeira em 1967 e 1968, a segunda em 1969, conforme a Tabela 2.

Tabela 2 Turmas das classes piloto de matemática - Colégio da Bahia - Centra ${ }^{36}$

\begin{tabular}{|c|c|c|c|c|c|c|c|c|c|c|c|c|}
\hline \multirow[b]{2}{*}{ Série } & \multicolumn{3}{|c|}{ Turma H } & \multicolumn{3}{|c|}{ Grupo A } & \multicolumn{3}{|c|}{ Grupo B } & \multicolumn{3}{|c|}{ Grupo E } \\
\hline & $1^{a}$ & $2^{\mathrm{a}}$ & $3^{\mathrm{a}}$ & $1^{\mathrm{a}}$ & $2^{\mathrm{a}}$ & $3^{\mathrm{a}}$ & $1^{a}$ & $2^{\mathrm{a}}$ & $3^{\mathrm{a}}$ & $1^{a}$ & $2^{\mathrm{a}}$ & $3^{\mathrm{a}}$ \\
\hline Alunos & 30 & $?$ & 19 & 37 & 27 & 23 & 40 & 33 & 21 & 33 & $?$ & $?$ \\
\hline Ano & 1966 & 1967 & 1968 & 1967 & 1968 & 1969 & 1967 & 1968 & 1969 & 1966 & $?$ & $?$ \\
\hline Professora & Lycia & Lycia & Lycia & Jolândia & Jolândia & Vera & Jolândia & Jolândia & Vera & $?$ & $?$ & $?$ \\
\hline
\end{tabular}

Segundo Lêda Jesuíno:

(...) essa classe experimental funcionou no Colégio Central, que era um dos grandes colégios da Secretaria de Educação da rede pública do Estado. Mas, acontece que para coordenar um projeto desse, era necessário estabelecer princípios definidos e ter uma filosofia de educação bastante clara e o meu papel foi coordenar toda essa parte teórica e a prática e a execução disso, que não era fácil. Mas, nós conseguimos fazer isso e com bastante êxito. ${ }^{37}$

Quando Lêda Jesuino disse que não foi fácil coordenar o projeto, de acordo com "princípios definidos" e uma "filosofia de educação bastante clara", supostamente, estava se referindo às dificuldades que foram enfrentadas já no 
primeiro ano da sua execução e que se repetiram de algum modo nos anos seguintes. Segundo ela, inicialmente, os alunos da turma H de 1966 não aceitaram a proposta, resistiram, não colaboraram, comprometendo a pontualidade, a assiduidade e a metodologia do trabalho ${ }^{38}$. Estes aspectos disciplinares e suas implicações para o projeto foram reiterados pela coordenadora em outra oportunidade:

Tinha a classe controle, porém eu devo lhe dizer, por falta de organização do Colégio, eu não pude fazer o controle como deveria ser feito. Não foi possível, não era possível, porque o colégio não tinha uma boa estrutura disciplinar, organizacional. Eu tentei, mas não consegui, não. Não consegui. Isso seria o ideal, todo experimento tem uma classe controle, mas eu não consegui, tentei... Todas as vezes que eu tentava, para fazer... não conseguia. Alunos faltando demais. A disciplina era ruim, no colégio em geral... nossa disciplina era bastante forte, fumar impossível, impossível. Chegar tarde de jeito nenhum... Nossa disciplina era bastante forte, só podia ser, senão, não podíamos trabalhar. ${ }^{39}$

A palavra "controle" pode ser considerada aqui de modo duplo. Por um lado, explicitamente, aparece como um qualificativo para a sala de aula comum que serviria para comparação com a sala de aula especial, a classe piloto. Contudo, há outro modo de considerá-la, como verbo "controlar", que está implícito no discurso de Lêda Jesuíno, mas subentendido no uso da palavra "disciplina". Ela se queixa que a escola não tinha "disciplina", isto é, não controlava os alunos, não controlava a assiduidade, a pontualidade, os hábitos dos alunos. Portanto, para que a experimentação científica pedagógica fosse realizada de modo efetivo nas classes piloto seria necessário controlar os alunos na assiduidade, pontualidade, nos hábitos.

Para corroborar esta nossa interpretação, trazemos aqui uma fala da professora Jolândia Serra Villa, que também se referiu à questão disciplinar, de outro modo, é verdade, mas corroborando a sua importância para o sucesso da experimentação:

Não sei como foi a seleção dos alunos, eles eram alunos normais, matriculados como alunos do Colégio da Bahia, de colégio público. Agora, um bom número deles tinha vindo do Colégio de Aplicação, eu acho, da Faculdade de Filosofia, está entendendo? Porque era um pessoal muito ligado ao conhecimento de D. Lêda. Então, os meninos eram assim... os que vieram para as classes-piloto, eram de um nível ótimo, alunos excepcionais em geral, alunos disciplinadíssimos, mas que vieram de outros colégios particulares... não sei bem quais eram os colégios, mas eu sei que basicamente era o Aplicação e se matricularam no Colégio da Bahia. Filhos de famílias também muito esclarecidas, que queriam um bom ensino para seus filhos, mas que não tinham, assim... muito pessoal das turmas normais do Colégio da Bahia, mas também não entro no mérito disso. Eu não sei muito. ${ }^{40}$

Por um lado, a turma $\mathrm{H}$ não apresentou bons resultados porque os alunos não aceitaram a proposta e resistiram, porque foram indisciplinados, por outro, os grupos A e B, pelo contrário, apresentaram excelentes resultados, dentre outras razões, porque seus alunos eram "de um nível ótimo, alunos excepcionais em geral, alunos disciplinadíssimos", que aceitaram a "disciplina", isto é, submeteram-se adequadamente ao controle disciplinar. E como este controle foi exercido? Lêda Jesuíno responde claramente a esta pergunta referindo-se ao emprego da técnica do sociograma:

- Mas, e o acompanhamento dos professores, qual a periodicidade desse acompanhamento? - Tudo acompanhado pela coordenação pedagógica (...) tudo está aqui, as fichas todas (...) tinha a psicóloga, Alice Costa, e tinha a coordenadora pedagógica (...). Nós tínhamos tudo, tudo. Número de ausências, frequência controlada, comportamento em sala de aula, perfil psicológico, está tudo aqui. $-E$ os pais?

- Os pais, reuniões constantes, à noite, reuniões mensais e muitas vezes mais de uma mensal (...) você já ouviu falar numa coisa que chama sociograma? (...) É uma técnica que tinha a orientadora educacional, professora Maria Augusta (...) ela faz questionários com os alunos e depois ela apura os questionários e é capaz de mostrar um mapeamento da classe, quem se agrupa com quem e por que interesse, interesse de leitura, interesse de cinema, interesse de brincar, interesse de ir 
a festas. Os pais adoravam saber com quem os seus filhos interagiam, chama-se sociograma (...)

- Então, pelos pais, não havia resistência?

- Nenhuma, ao contrário. Sabe quem comparecia? Dr. Jorge Calmon, pessoas intelectuais, claro, tinham interesse em seus filhos (...)

- Então, havia uma integração escola - sociedade?

- Muito, muito grande. Interação muito grande. Com os pais, o serviço social... era Odete, ela está aposentada (...) Modelo do termo de compromisso dos pais e responsáveis pelo aluno. Tudo isso era muito bem controlado. Eu vim de uma experiência fantástica, eu dirigi o Colégio de Aplicação seis anos. Conhecia muito bem tudo isso. Para mim, não era novidade. ${ }^{41}$

Aqui, a palavra "controle" não está mais escondida, está explicita e assume 0 caráter de técnica científica exercida por profissionais especializados e competentes: o sociograma, a psicóloga, a pedagoga e a assistente social. Elas controlavam tudo! A frequência, o perfil psicológico, comportamento em sala de aula, os interesses, as interações sociais. Começam então a ficar bem caracterizados os "princípios" e a "filosofia de educação" mencionados por Lêda Jesuíno.

Estes "princípios" e esta "filosofia da educação" são complementados pelos aspectos metodológicos e didáticos das aulas de matemática nas classes piloto. Em primeiro lugar, as aulas de matemática tinham uma carga horária maior nas classes piloto do que nas classes normais: cinco a seis horas nas primeiras, cinco a quatro horas nas segundas. Além destas aulas pela manhã, havia o horário complementar pela tarde, que era um horário de estudos, uma espécie de estudo dirigido: os alunos recebiam orientação, faziam estudos das apostilas, resolviam as listas de exercício, que revisavam a aula anterior e preparavam para as aulas seguintes, e eram cobrados, pois havia testes todos os dias, testes rápidos, de 10 a 15 minutos, para não deixar 0 assunto acumular, para estar estudando sempre. Além destes testes, havia arguições e provas, de quinze em quinze dias. Portanto, em suma, a avaliação era sistemática e constante.

A inovação metodológica e didática tornou-se possível porque as salas tinham menos alunos: enquanto as classes piloto tinham em torno de 30 alunos, as salas comuns tinham em torno de 50. Havia um acompanhamento individual mais direcionado aos alunos, que permitia identificar e sanar dificuldades particulares no ritmo de aprendizagem dos alunos. Além da aula expositiva, os alunos também trabalhavam o conteúdo em grupo ou individualmente, a partir de problemas, situações para as quais eles sugeriam as etapas a serem cumpridas e as possíveis soluções, promovendo o desenvolvimento do raciocínio lógico. Eram aulas dinâmicas e participativas, os alunos iam frequentemente ao quadro para resolver os problemas propostos ou para apontar um caminho para a solução:

Com relação às aulas, eram participadas e tinha exercício resolvido no quadro (...) abria a caderneta e identificava um aluno e ele ia dizer como resolver aquele exercício. Necessariamente, ele não ia ao quadro resolver, mas ele manifestava uma sugestão de como resolver. E aí, muitas vezes, sorteávamos outro para discutir... De alguma forma, procurávamos deixar a aula mais dinâmica e não ficar somente aceitando... Buscava sempre colocar assim uma maneira de buscar direções diferentes, sugestões diferentes para se chegar num consenso e isso eu acho que enriquece muito. E para nós foi muito gratificante! ${ }^{42}$

Estes "princípios", esta "filosofia", que se concretizaram metodologicamente, didaticamente, nas salas de aula das classes piloto, contavam com uma adesão a priori dos alunos, pois a participação nas classes piloto pressupunha um conhecimento e um comprometimento prévio, uma adesão ao planejamento e às condições que seriam seguidos:

Então, era um Colégio Estadual, onde o aluno tinha o acesso da mesma forma que todos, não havia distinção por causa disso. Agora, ele manifestava não só o desejo como a disponibilidade, está certo? Trabalhar com a classe ele não tinha a necessidade de curso complementar. ${ }^{43}$

Portanto, embora não houvesse uma seleção previa propriamente dita, explícita, havia explicitamente uma comunicação prévia, por meio da qual era dado aos alunos - e às suas famílias, como veremos a seguir - conhecimento 
sobre a "filosofia" e o modo de trabalho das classes piloto. Em primeiro lugar, os alunos ficavam cientes que estariam fazendo uma opção: as classes piloto no lugar dos cursos complementares, isto é, quem quisesse fazer vestibular para medicina ou engenharia, por exemplo, não faria os respectivos cursos complementares, aceitaria ficar somente com as classes piloto. Em segundo lugar, ao fazer esta opção, os alunos estariam se comprometendo explicitamente com a dedicação aos estudos, com a disponibilização do tempo necessário para o cumprimento das tarefas, das atividades complementares, para o acompanhamento psicopedagógico, no Serviço de Orientação Educacional (SOE).

Contudo, em alguns casos houve uma seleção a posteriori, não apenas na turma $\mathrm{H}$, mas também nos grupos A e B:

Então, com esses livros e com a metodologia um pouco diferente das outras turmas, os alunos, que alguns até nem gostavam de Matemática, começaram a adorar Matemática. Eu tive verdadeira surpresa, porque nas provas, o mais difícil em raciocínio, mais encrencado que eu colocasse, as notas eram excelentes. Não tinha um aluno que não gostasse de Matemática. Uns poucos das classes-piloto, que não estavam muito adaptados a essa metodologia de Matemática, de Desenho, de Física, que era mais ou menos semelhante, de Química, se transferiram, deixaram as classes-piloto. Então, no segundo ano, o número já foi um pouco menor, está entendendo? Eu acho que, justamente, devido a um trabalho do aluno. Participava muito. Então, aquele aluno mais tímido, que gostava menos de estudar foi deixando a classe-piloto, mas não foram muitos, não. Coisa de cinco ou seis em cada turma. ${ }^{44}$

Aqui, perguntamo-nos se não esteve presente implicitamente o princípio da homogeneização, defendido por Isaías Alves nos anos 1930-1940, como condição necessária para a melhoria do desempenho escolar. Porque, de fato, constatamos um desempenho ótimo - na faixa de $100 \%$ de aprovação no vestibular, como veremos a seguir - de turmas com um número reduzido de alunos, que se não foram selecionados explicitamente por algum exame prévio ou teste de inteligência, foram selecionados previamente por um processo de adesão informada e esclarecida e posteriormente pelo próprio desempenho e adaptação ao modus operandi das classes piloto: aqueles poucos que não se adaptavam às classes piloto, por qualquer motivo que fosse, mesmo depois do acompanhamento individual, seja na sala de aula, pela professora, seja no serviço psicopedagógico, pela psicóloga ou pela pedagoga, eram transferidos para as salas comuns.

Também havia o conhecimento prévio e a adesão das famílias, que acompanhavam sistematicamente 0 que seus filhos faziam nas classes piloto. Mais do que isto, havia o apoio e o respaldo das famílias dos alunos, dos pais e responsáveis, inclusive material e financeiro:

Meninos bem inteligentes, de uma escolaridade espetacular, que a maioria deve ter vindo do Colégio de Aplicação, não sei bem... não me lembro. Na época até eu sabia, mas 43 anos depois eu não me lembro assim, mas eu acho que a maioria era do Colégio de Aplicação e de famílias que tinham escolaridade superior em casa, que tinha biblioteca, que tinha livros, que podia comprar livro porque tinha dinheiro para comprar livro, está entendendo? Podia pagar para os filhos irem para passeio ver a cachoeira de Paulo Afonso (...) ver coisas assim in loco. Tinham esses recursos que hoje é uma das grandes dificuldades do ensino, né? As crianças são carentes, às vezes não tem nem alimentação, né? ${ }^{45}$

Este conhecimento, adesão, apoio e respaldo das famílias estão explícitos em todas as entrevistas realizadas. Há inclusive uma insinuação sutil de que algumas famílias das relações de Lêda Jesuíno, após serem informadas sobre as classes piloto, transferiram seus filhos do Colégio de Aplicação e de escolas particulares de Salvador para seguirem as classes piloto do Central. Ora, não é novidade para qualquer um que compartilhe a memória coletiva sobre o Colégio da Bahia a sua fama, mantida justamente até a década de 1960, de receber e formar os filhos das classes dirigentes e médias da sociedade baiana. Em outras palavras, o Colégio da Bahia sempre foi, até a década de 1960, uma escola das "elites" baianas, onde eram formados no secundário os futuros médicos, advogados, magistrados, engenheiros, dentre outros, que se tornavam proeminentes nas esferas empresariais, políticas e intelectuais. 
Estaria a experimentação pedagógica nas classes piloto apenas replicando de algum modo diferente este padrão? Estaria seu teor "revolucionário" apenas e tão somente nas metodologias e conteúdos ensinados, amparados em "princípios" e "filosofia" com forte e declarado caráter disciplinador, controlador?

Quais foram os resultados obtidos nestas turmas $A$ e $B$ das classes piloto, que sustentaram uma avaliação positiva da experimentação pedagógica realizada, ao menos por parte da equipe envolvida, mas que também se cristalizou na memória coletiva da educação na Bahia? Nas palavras de Lêda Jesuíno, Jolândia Vila, Vera Baqueiro e do ex-aluno César Jambeiro:

- Essa experiência com as classes-piloto tinha esse objetivo, voltado para o vestibular, conduzir os alunos à aprovação no vestibular?

- Tinha, mas nem tanto. O que nós queríamos mesmo não era isso. O objetivo básico era revolucionar metodologicamente o ensino de ciências exatas e ciências humanas. ${ }^{46}$

- E, depois eles fizeram vestibular, sem tomar cursinho de vestibular de qualquer disciplina. Eles fizeram com os ensinamentos e o traquejo das classes piloto. Praticamente todos, se não foram todos, passaram em vestibular de faculdade pública, das federais (...). Então eles fizeram todos na Universidade Federal e, praticamente, todos passaram. Além de todos terem passado, passaram bem classificados. Além disso, eles... São, hoje, alguns eu até ainda tenho contato, profissionais de todo sucesso, está entendendo? Nas suas áreas (...) Engenharia, Arquitetura, Economia, enfim (...) Medicina, tem muitos médicos (...) Enfermagem, todas essas carreiras. Foi realmente uma experiência de muito sucesso. ${ }^{47}$

- Realmente foi tão boa a experiência, nós sentimos não ter continuado. O pessoal da classe piloto passou... quando escolheu assim para o vestibular, o resultado foi, se eu não me engano, se não foi 100\% foi muito próximo a $100 \% .^{48}$

- Não houve nenhum preparatório; foi o próprio curso, dado durante três anos, que nos preparou, vamos dizer assim, para o vestibular e para vida profissional. Fizemos o $1^{\circ}$ vestibular, passamos, passei em Física, estudei durante um ano no Instituto, porém senti que Física ainda não era o que eu procurava. Voltei a fazer outro vestibular sem participar de cursinho preparatório nenhum, somente com o ensino que eu tinha recebido no Colégio Estadual da Bahia [...] Fiz então vestibular para Administração de Empresas, passei e me formei em Administração de Empresas (...). Posteriormente, fiz outro vestibular, para Ciências Contábeis, passei também sem cursinho nenhum, graças ainda àquela preparação que nós tivemos [...] E sinto, sinceramente, que o Governo, a Universidade, quem quer que seja, não tenha se interessado por essa experiência [...] Se o Colégio da Bahia tivesse seguido essa experiência, essa modernização e mudança que foi proposta, nós teríamos um ensino bem diferente do que hoje é dado (... $)^{49}$

Na década de 1960, ainda vigorava a legislação educacional que dividia o sistema de ensino em duas fases: 0 primário, incluindo o exame de admissão; o secundário, que tinha o curso o ginasial, o curso científico ou o clássico. Desta forma, o ensino secundário tinha um caráter reconhecidamente propedêutico para os cursos universitários, embora os candidatos tivessem invariavelmente que fazer cursos preparatórios, complementares, os chamados pré-vestibulares, para as diversas carreiras, a saber, os preparatórios para o curso médico, para engenharia, para direito. Outra característica importante do ensino secundário era o seu caráter elitista, visto que uma parcela muito reduzida da população em idade escolar o alcançava. Isto é bem conhecido na literatura educacional brasileira em geral e na historiografia da educação brasileira, em particular. Portanto, cabe aqui um questionamento: em que medida pode ser considerada realmente "revolucionária" uma experimentação pedagógica que se caracterizou fundamentalmente, como vimos anteriormente, pelo ensino - aprendizagem de conteúdos diferenciados é verdade, mas conduzidos metodológica e didaticamente sob "princípios" e "filosofia" embasados essencialmente por um discurso de controle e disciplinamento?

\section{Considerações finais}

Em 1964, quando houve o golpe de estado, uma das primeiras ações repressivas das forças golpistas foi justamente a invasão da residência universitária da UFBA, quando foram presos indistintamente, de modo arbitrário e 
violento, todos aqueles que lá se encontravam. Este foi o início de uma estratégia organizada e sistemática de repressão a toda atividade estudantil que não se enquadrasse em certos padrões considerados como inofensivos à hegemonia do governo ditatorial que se instituía.

Este tipo de ação se repetiu por ocasião da repressão às manifestações e protestos contra a proibição da representação da peça teatral de autoria do estudante secundarista Carlos Sarno, quando a residência universitária foi novamente violentamente invadida na noite em que a peça seria representada, ou quando o Mosteiro de São Bento foi ameaçado de invasão caso permitisse a realização da referida peça nas suas instalações..$^{50}$

Posteriormente, dando continuidade a esta estratégia e complementando-a, as "comunidades de segurança e informação" ligadas ao governo ditatorial51 atuaram também de forma organizada e sistemática acompanhando, discriminando e perseguindo estudantes e professores secundários e universitários cujos ideais e atividades, individuais ou coletivas, não se enquadrassem em certos padrões considerados como inofensivos à hegemonia do governo ditatorial instituído. Foram centenas ou milhares de casos de estudantes que tiveram suas matrículas suspensas ou impedidas de serem renovadas, sob a pressão das comunicações sigilosas endereçadas às autoridades educacionais, escolares ou universitárias, ameaçadas pela invocação das leis discricionárias outorgadas pela própria ditadura.52

Particularmente, em 1966, por ocasião das manifestações e protestos estudantis referidos neste trabalho, que reuniram secundaristas e universitários, o próprio Ministro da Educação dirigiu-se às autoridades educacionais locais exigindo a manutenção da ordem escolar e da regularidade dos trabalhos escolares, a permanência nas salas de aula, assegurando a normalidade escolar, de acordo com a Lei 4464, de novembro 1964, imposta pela ditadura:

FATO 3.4-Ofício 4055, circular, de 15 de setembro de 1966, assinado pelo Vice-Reitor em exercício, Adriano Pondé, e enviado aos diretores de Unidades, transcreve "para os devidos fins e necessárias providências" texto do Ministro da Educação, Raymundo Moniz de Aragão, nos termos abaixo: "Tendo em vista atual inquietação estudantil lembro vossa Magnificência que, acordo legislação vigente, et as universidades et diretores Unidades manutenção ordem escolar. Recomendo, assim, suas providencias sentido chamar atenção diretores escolas necessidade manter regularidade trabalhos escolares, impondo-se atuação direta junto estudantes persuadindo a permanecerem em aulas, assegurando normalidade vida estudantil. Lembro ser ilegal qualquer movimento greve por parte estudantes e esclareço artigo 17 Lei 4464, novembro 1964, prescreve incorrer diretores escolas ou reitor universidade, falta grave se por atos, omissão ou tolerância permitirem ou favorecerem o não cumprimento referida Lei. Governo confia ação Vossa Magnificência sentido ser respeitada legislação vigente e salvaguarda autonomia universidade. Cordialmente, Raymundo Moniz de Aragão, Ministro da Educação e Cultura." ${ }^{53}$

Aqui, gostaríamos de destacar a semelhança impressionante entre o discurso disciplinador e controlador adotado pelas autoridades do governo ditatorial e o discurso disciplinador e controlador adotado pela professora Lêda Jesuíno, coordenadora do projeto de experimentação pedagógica desenvolvido nas classes experimentais do Colégio da Bahia. Por um lado, as autoridades do governo ditatorial cobravam providências e ameaçavam as autoridades universitárias e escolares para que atuassem diretamente junto aos estudantes persuadindo-os no sentido de permanecerem em sala de aula, mantendo-se a ordem, a normalidade e a regularidade dos trabalhos escolares. Por outro, Lêda Jesuíno, como mostramos anteriormente neste trabalho, criticou a falta de disciplina e de controle dos alunos no Colégio da Bahia, a falta de assiduidade e de pontualidade, valendo-se desta falta de disciplina e de controle para explicar as razões do insucesso da experimentação pedagógica na turma $\mathrm{H}$. Mais do que isto, destacou a disciplina e o controle como condições necessárias para que fossem bem sucedidas as experimentações realizadas nos grupos $A$ e $B$, detalhando inclusive as técnicas que foram utilizadas para o exercício da disciplina e do controle.

0 resultado das duas práticas disciplinadoras e controladoras foram assimétricos: por um lado, muitos estudantes que desobedeceram a lei e a ordem impostas pelas ditadura tiveram suas matrículas suspensas ou impedidas de serem renovadas, por outro, 100\% dos estudantes que obedeceram aos princípios disciplinares e controladores que fundamentaram as experimentações pedagógicas das classes piloto, que conseguiram se submeter as suas técnicas 
psicopedagógicas e didáticas, foram aprovados no vestibular dos mais concorridos cursos da UFBA, obtendo posteriormente suas matrículas.

Esta semelhança não nos parece casual. Não foi por acaso que Lêda Jesuíno declarou destemidamente sua simpatia e seu apoio aos militares que integraram o governo ditatorial:

- A senhora se refere à Ditadura?

- Não, a Ditadura nunca me atrapalhou. Ao contrário, eu sempre trabalhei com o ministro Passarinho na maior tranquilidade do mundo. Adorei trabalhar com militares porque são pessoas que cumprem suas palavras, muito diferentes dos políticos atuais (...). Faço questão de dizer e digo na frente de qualquer petista (...). Um grande ministro! Um grande ministro! ${ }^{54}$

Lembrando Michel Foucault, o poder não é exercido apenas pelo Estado, de cima para baixo, nem também apenas de modo violento, mas se difunde por todas as instâncias da sociedade, sendo exercido também de baixo para cima, de modo sutil. Segundo ele, na modernidade, são instituições como a escola que exercem o poder disciplinador e controlador dos corpos e das mentes de modo difuso e sutil, valendo-se de técnicas, muitas vezes, de técnicas científicas.

No início deste trabalho, relatamos uma trajetória da concepção de experimentação pedagógica de John Dewey, que foi trazida para o Brasil por educadores brasileiros como Anísio Teixeira, Isaías Alves e Luiz de Mattos, que fizeram cursos nos Estados Unidos e tomaram conhecimento desta concepção. Interessante retomar aqui, nestas considerações finais, que Anísio Teixeira e Isaías Alves se aproximaram e se afastaram em certos momentos das suas trajetórias pessoais e profissionais por conta de certas convergências e divergências políticas e ideológicas, dentre outras possíveis razões. Particularmente, se o conceito de experimentação pedagógica de John Dewey, compartilhado pelos dois, tem uma reconhecida fundamentação democrática e liberal, do ponto de vista político e ideológico, os testes de inteligência e a homogeneização das classes, defendidos por Isaías Alves, foram descartados por Anísio Teixeira justamente pela avaliação de que eram contraditórios com seus ideais e propostas liberais e democratizantes para a educação no Distrito

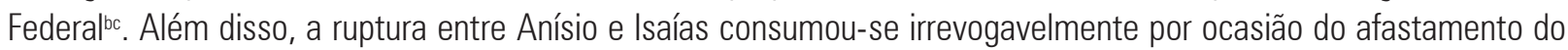
primeiro da Diretoria Geral de Instrução Pública do Distrito Federal sob acusações e perseguições ideológicas, quando da implantação do Estado Novo, resultando no encerramento da experiência pedagógica pioneira e inicial que Anísio Teixeira concebera e implantara no Instituto de Educação da Universidade do Distrito Federal. Contudo, foi retomada no âmbito do próprio Estado Novo por Isaías Alves e por Luiz de Mattos, quando conceberam as respectivas escolas de aplicação das faculdades de filosofia da Bahia e do Rio de Janeiro. As limitações para a efetiva implementação da experimentação pedagógica, nestes dois casos, foram de ordem legal e prática, como vimos, pois a legislação vigente nas décadas de 1940 e 1950 não possibilitavam efetivamente as experimentações pedagógicas, em que pese a pouquíssima adesão das faculdades de filosofia às escolas de aplicação.

Na Bahia, quando a experimentação pedagógica ocorreu efetivamente, na década de 1960, estiveram presentes liderando os projetos duas ex-alunas de Isaías Alves: Martha Dantas, na Seção Científica de Matemática do CECIBA, que conduziu projetos inovadores e modernizantes para o ensino da matemática, principalmente, em classes ginasiais da Escola de Aplicação da UFBA, e Lêda Jesuíno, que coordenou as classes piloto do Colégio Estadual da Bahia.

Martha Dantas, além da influência de Isaías Alves, enriqueceu a sua formação pessoal e profissional pelas experiências que vivenciou nas suas muitas viagens ao exterior, principalmente, para a Europa, onde acompanhou de perto as discussões em torno das reformas educacionais que ocorreram na França na década de 1950, sobre as concepções inovadoras e modernizantes para o ensino secundário, em geral, e para o ensino da matemática, em particular, que incorporaram, por um lado, as noções e propostas pedagógicas, metodológicas e didáticas da Escola Nova, por outro, as concepções e conteúdos modernos da matemática e da metodologia do ensino da matemática. Recém-saídos da II Guerra, de um período de violência militar e de arbítrio político, os europeus, de modo geral, e os franceses, em particular, pressupunham que as reformas educacionais e a renovação do ensino de ciências e matemática, em particular, eram condições necessárias para a reconstrução política democrática e o desenvolvimento econômico. Sob estas influências 
que ela constituiu as referências para conduzir um projeto de experimentação pedagógica, principalmente, na Escola de Aplicação da UFBA entre 1965 e 1969.

No caso das classes piloto do Central, coordenadas por Lêda Jesuíno, que foi o foco principal deste trabalho, acabamos por constatar certos aspectos e características da experimentação pedagógica conduzida nas salas de aula de matemática que, poderíamos dizer, são surpreendentes, no mínimo: o sucesso das classes piloto do Central teve como condição necessária um rigoroso princípio disciplinador e controlador da prática pedagógica de ensino e aprendizagem; para além disso, encontramos subliminarmente, de modo sutil, quase imperceptível, um princípio homogeneizador que regulou a constituição destas classes. Em suma, de uma concepção liberal democrática, que constituiu metodologias e didáticas centradas no aluno, na sua atividade, chegamos a encontrar uma experimentação pedagógica em classes piloto que pressupôs uma concepção disciplinadora e controladora análoga, semelhante, àquela prescrita pelas autoridades da ditadura, que desenvolveu metodologias e didática centradas nas atividades coletivas e individuais dos alunos, é verdade, não obstante protegidas pela seleção homogeneizadora dos alunos, realizada implicitamente a priori ou a posteriori, conforme tentamos mostrar neste trabalho.

\section{Notas e referências bibliográficas}

Mariana Moraes Lobo Pinheiro é mestre em Ensino, Filosofia e História das Ciências pela Universidade Federal da Bahia e Universidade Estadual de Feira de Santana (2012). E-mail: pinheiromml@gmail.com.

Janice Cássia Lando é doutora em Ensino, Filosofia e História das Ciências pela Universidade Federal da Bahia e Universidade Estadual de Feira de Santana (2012). E-mail: janicelando@gmail.com.

André Luis Mattedi Dias é doutor em História Social pela Universidade de São Paulo (2002). E-mail: andre.luis.mattedi.dias@gmail.com.

1 DEWEY, John. The school and society. Chicago: University of Chicago, 1915, p. 87-88.

2 MAYHEW, Katherine Camp, EDWARDS, Anna Camp.The Dewey school: the laboratory school of the University of Chicago, 1896-1903. New York: D. Appleton-Century Co, 1936; FALLACE, Thomas. Repeating the race experience: John Dewey and the history curriculum at the University of Chicago Laboratory School. Curriculum Inquiry, v. 39, n. 3, p. 381-405, jun. 2009.

3 VALDEMARIN, Vera Teresa. História dos métodos e materiais de ensino: a escola nova e seus modos de uso. São Paulo: Cortez, 2010, p. 31; GARCíAVERA, Nylza Offir. La pedagogía de proyectos en la escuela: una revisión de sus fundamentos filosóficos y psicológicos. Magis, Revista Internacional de Investigación en Educación, v. 4, n. 9, p. 685-707, 2012.

4 TEACHER'S COLLEGE COLUMBIA UNIVERSITY. HISTORICAL TIMELINE. Disponível em < http://www.tc.columbia.edu/abouttc/timeline/> . Acesso em: 09 ago. 2014.

5 HEFFRON, John M. Lincoln School. Encyclopedia of Education. Disponível em: <http://www.encyclopedia.com>. Acesso em: 09 ago. 2014.

6 WARDE, Mirian Jorge. Estudantes Brasileiros no Teacher's College da Universidade de Columbia: do aprendizado da comparação. Disponível em: $<$ http://www.sbhe.org.br/novo/congressos/cbhe2/pdfs/Tema1/0114.pdf>. Acessado em: 09 jul. 2011.

7 BITTENCOURT, Agueda Bernadete. Trajetória de herdeiro entre dois projetos políticos. Educação e Pesquisa, v. 35, n. 1, 2009, p. $106-107$.

8 DAVILA, Jerry. Sonhos americanos, realidades autoritárias: encontros entre a sociedade democrática de John Dewey e a era Vargas. Revista Educação em Questão, Natal, v. 24, n. 10, p. 7-28, set./dez. 2005, p. 15.

9 ROCHA, Ana Cristina Santos Matos. 0 que fazer com os rudes? Isaías Alves e as divergências sobre o papel da inteligência na organização escolar (19301942). 2011. Dissertação (Mestrado em História, Política e Bens Culturais) - Fundação Getúlio Vargas, CPDOC, p. 59.

10 Idem.

11 LANDO, Janice Cássia. Práticas, inovações, experimentações e competências pedagógicas das professoras de matemática no Colégio de Aplicação da Universidade da Bahia (1949-1976). 2012. Tese (Doutorado em Ensino, Filosofia e História das Ciências) - Universidade Federal da Bahia, p. 57.

12 BARROS, Zilma Gomes Parente de. Redefinição conceitual dos colégios de aplicação. 1975. Dissertação (Mestrado em Educação) - Universidade Federal da Bahia, p. 21.

13 Luiz Narciso Alves de Mattos, com o nome D. Xavier de Matos, foi monge beneditino, formado em Filosofia, ocupou a cátedra de Psicologia da Faculdade de Filosofia Sedes Sapientiae (1933-1937) e da Faculdade de Ciências e Letras de São Bento (1935-1939). Em 1939, deixou a ordem beneditina e tornou-se catedrático de Didática Geral e Especial da Faculdade Nacional de Filosofia da Universidade do Brasil. CARVALHO, Merise Santos de. Construindo uma didática experimental no Rio dos anos 50/60. In: CONGRESSO BRASILEIRO DE HISTÓRIA DA EDUCAÇÃO, 1., 2000, Rio de Janeiro. Anais... Rio de Janeiro, 2000.

14 Outrossim, em agosto de 1949, a professora Eleonora Lobo Ribeiro, assistente de didática especial da matemática da Faculdade Nacional de Filosofia, visitou a Faculdade de Filosofia da Bahia e o Ginásio de Aplicação, onde lecionou um curso com duração de uma semana. Em 1957 e 1959, Eleonora Ribeiro apresentou trabalhos sobre a experimentação pedagógica desenvolvida no Colégio de Aplicação do Rio de Janeiro nos congressos de ensino da 
matemática realizados em Porto Alegre e no Rio de Janeiro, respectivamente. LANDO, Janice Cássia. op. cit., p. 144.

15 AMADO, Gildásio. Instruções sobre a natureza e a organização das classes experimentais da Diretoria do Ensino Secundário. Revista Brasileira de Estudos Pedagógicos, n. 72, v. XXIX, p. 73-83, abr.jun., 1958, p. 80.

16 WARDE, Mirian Jorge; RIBEIRO, Maria Luisa Santos. 0 contexto histórico da inovação educacional no Brasil. In: GARCIA, Walter E. (Coord.). Inovação educacional no Brasil: problemas e perspectivas. São Paulo: Cortez /Autores Associados, 1980, p. 200-203.

17 SEMINÁRIO SOBRE AS EXPERIÊNCIAS INOVADORAS NA EDUCAÇÃO BAIANA NA DÉCADA DE 1960. Salvador: Universidade do Estado da Bahia, 2001.

18 DIAS, André Luís Mattedi, LANDO, Janice Cássia, FREIRE, Inês Angélica. Formação de professores na Bahia: os cursos de matemática e de didática da Faculdade de Filosofia (1943-1968) In: FERREIRA, Ana Cristina; BRITO, Arlete de Jesus, MIORIM, Maria Ângela (Org.). História de formação de professores que ensinaram matemática no Brasil. Campinas: Ilion, 2012, p. 129.

19 DIAS, André Luís Mattedi. Martha Dantas at Centre International d'Études Pédagiques (Sèvres, 1953): a contribution for the History of Mathematics Education in Brazil In: INTERNATIONAL CONFERENCE ON THE HISTORY OF MATHEMATICS EDUCATION, 2., 2012, Caparica, Portugal. Proceedings... Caparica, Portugal: Unidade de Investigação Educação e Desenvolvimento, FCT / UNL, 2012, v.1, p. 141-148.

20 LECOQ, Tristan, LEDERLE, Annick. Le Centre international d'études pédagogiques à Sèvres Une histoire plurielle d'un lieu singulier . Sèvres: Centre International d'Études Pédagogiques , 2010.

21 D'ENFERT, Renaud. Matemáticas modernas e métodos ativos: as ambições reformadoras dos professores de matemáticas do secundário na Quarta República francesa (1946-1958). História da Educação, Pelotas, v. 14, n. 32, p. 7-30, Set/Dez 2010.

22

Idem.

23 Idem.

24 LECOQ, Tristan, LEDERLE, Annick. op. cit., 2010, p. 71.

25 FREIRE, Inês Angélica Andrade. Ensino de Matemática: iniciativas inovadoras no Centro de Ensino de Ciências da Bahia (1965-1969). Salvador, 2009. Dissertação (Mestrado em Ensino, Filosofia e História das Ciências), UFBA-UEFS, p. 22.

26 BORGES, Regina Maria Rabello, SILVA, Ascendino Flávio Dias e, DIAS, André Luís Mattedi. Cultura e educação científica e tecnológica em centros de ciências no Brasil In: BORGES, Regina Maria Rabello (Org.). Educação e cultura científica e tecnológica. Porto Alegre: EDIPUCRS, 2012, p. 23-40.

27 SEMINÁRIO SOBRE AS EXPERIÊNCIAS INOVADORAS NA EDUCAÇÃO BAIANA NA DÉCADA DE 1960. Salvador: UNEB, 2001.

28 LANDO, op. cit., 2012, p. 215

29 DANTAS, Martha Maria de Souza et al. Matemática Moderna I. Salvador: UFBA, 1967. p. IV.

30 FREIRE, op. cit., 2009; BRAGA, Maria Nilsa Silva. O Programa de Treinamento e Aperfeiçoamento de Professores de Ciências Experimentais e Matemática - PROTAP (1969-1974): sua contribuição para a modernização do ensino de matemática. 2012. Dissertação (Mestrado em Ensino, Filosofia e História das Ciências) - Universidade Federal da Bahia.

31 O CECIBA teve um Conselho Técnico Administrativo, um Diretor Executivo, um Assessor Técnico Administrativo, seis seções científicas (Biologia, Educação, Física, Iniciação a Ciências, Matemática, Química), três seções técnicas e uma administrativa.

32 FICO, Carlos. Versões e controvérsias sobre 1964 e a ditadura militar. Revista Brasileira de História. São Paulo, v. 24, n. 47, p. 29-60, 2004, p. 33; ZACHARIADES, Grimaldo Carneiro (Org.). Ditadura Militar na Bahia: novos olhares, novos objetos, novos horizontes. Salvador: EDUFBA, 2009.

33 Uma das primeiras ações repressivas dos golpistas em 1964 foi invadir a residência estudantil da UFBA e prender todos os presentes indistintamente e arbitrariamente. BRASIL. Ministério da Educação. Universidade Federal do Estado da Bahia. Comissão Milton Santos de memória e verdade: relatório final. Salvador, 2014, p. 20.

34 DIAS, José Alves. A subversão da ordem: manifestações de rebeldia contra o regime militar na Bahia. 2002. Dissertação (Mestrado em História) Universidade Federal da Bahia; BRITO, Antônio Maurício Freitas de. Capítulos de uma história do movimento estudantil na UFBA (1964-1969). 2003. Dissertação (Mestrado em História) - Universidade Federal da Bahia.

35 Formada em Filosofia na primeira turma da Faculdade de Filosofia da Bahia, em 1945, iniciou a carreira como professora secundária, nos colégios Sophia Costa Pinto e Ypiranga. Depois, lecionou por 12 anos no Departamento de Filosofia da Faculdade de Filosofia. De 1957 a 1964, foi subdiretora do Colégio de Aplicação. Em 1964, passou a integrar a comissão do Colégio Universitário no Departamento Cultural da UFBA. Em 1966, assumiu a coordenação da Seção de Educação do CECIBA, para assumir a coordenação das classes experimentais do Central logo a seguir. Finalmente, em 1968, assumiu a direção e implantação da Faculdade de Educação, por ocasião da Reforma Universitária.

36 Fonte: Arquivo FACED, UFBA.

37 SANTOS, Lêda Jesuíno dos. Entrevista. Salvador, 28.02 e 21.03.2011. In: RAMOS. Mariana Moraes Lobo Pinheiro. Modernização da matemática na Bahia: a experiência com classes-piloto no Colégio Estadual da Bahia - Central (1966-1969). 2012. Dissertação (Mestrado em Ensino, Filosofia e História das Ciências) - Universidade Federal da Bahia, Anexo, p. 94.

38 SANTOS, Lêda. Jesuíno dos. (Org.). Classes-piloto do Colégio Central da Bahia: uma vivência pedagógica dos anos 60. Cadernos IAT. Salvador, n. 5, dez. 1989.

39 SANTOS, apud, RAMOS, op. cit., 2012, p. 96.

40 VILA, Jolândia Serra. Entrevista. Salvador, 13.04.2011. In: RAMOS, op. cit., 2012, Anexo, p. 131.

41 SANTOS, apud, RAMOS, op. cit., 2012, p. 100.

42 WASCONCELLOS, Vera Lúcia da Conceição Baqueiro apud, RAMOS, op. cit., 2012, Anexo, p. 149.

43 WASCONCELLOS apud, RAMOS, op. cit., 2012, p.146.

44 VILA, apud, RAMOS, op. cit., p. 132.

$45 \quad$ Idem, p. 138 
46 SANTOS, apud, RAMOS, op. cit., 2012, p. 100.

47 VILA, apud, RAMOS, op. cit., p. 138.

48 WASCONCELLOS apud, RAMOS, op. cit., 2012, p. 149.

49 JAMBEIRO, César. Entrevista. In: SANTOS, Lêda Jesuíno dos (Org.). Op. cit., 1989, p. 135.

50 BRASIL. Ministério da Educação. Universidade Federal do Estado da Bahia, op. cit. p. 20.

51 FICO, Carlos. Versões e controvérsias sobre 1964 e a ditadura militar. Revista Brasileira de História. São Paulo, v. 24, n. 47, p. 29-60, 2004 , p. 33.

52 BRASIL. Ministério da Educação. Universidade Federal do Estado da Bahia. UFBA. Op. cit.

53 Idem.

54 SANTOS, apud, RAMOS, op. cit., 2012, p. 99.

55 ROCHA, op. cit., 2011.

[Recebido em Dezembro de 2013. Aprovado para publicação em Setembro de 2014.] 